\title{
Seguridad ciudadana y policía comunitaria en contexto de cambio político y social
}

\author{
Citizen's safety and community police in the context \\ of social and political change
}

\begin{abstract}
Bertha García Gallegos ${ }^{1}$
bjgarcia@uio.satnet.net

\section{Resumen}

El artículo ilustra, desde una perspectiva sistémica, el rol de la policía nacional de Ecuador en las dinámicas de la política de seguridad ciudadana. Asimismo, analiza la convergencia entre los modelos de gestión política de la seguridad pública y ciudadana de los gobiernos locales y del Gobierno nacional en Ecuador con el objetivo de registrar los aportes de la institución policial al concepto y prácticas de la Policía Comunitaria y a la construcción de confianza con la comunidad.
\end{abstract}

\section{Palabras claves}

Seguridad ciudadana, políticas de seguridad, modelos de gestión de seguridad, Policía nacional.

\section{Abstract}

The article illustrates, from a systemic perspective, the rol of the national police force in Ecuador in the dynamics of citizen's safety. Likewise, it analyses the convergence between the political management models for public safety and citizenship of local governments and Ecuador's national government with the purpose of registering the contributions of the police force institution to the concept and practice of Communitarian Police and the trust-building process in the community.

\section{Keywords}

Citizen's safety, safety policies, management models for public safety, National Police force.

Forma sugerida de citar: GARCÍA GALLEGOS, Bertha (2013). "Seguridad ciudadana y policía comunitaria en contexto de cambio político y social". En: Universitas, XI (19), julio-diciembre, p. 49-72. Quito: Editorial Abya Yala/Universidad Politécnica Salesiana.

1 Doctora, profesora de la Pontificia Universidad Católica del Ecuador (PUCE), Directora del Programa internacional Democracia, Seguridad y FF.AA. 


\section{Introducción}

La severa crisis económica y política que experimentó el Ecuador durante la década del 90 del siglo XX y comienzos del XXI, fue uno de los factores para el retraso de las reformas al sector de la seguridad pública y ciudadana desde una perspectiva nacional, en comparación con otros países de Latinoamérica. ${ }^{2}$ Una propuesta integral de seguridad empezó a delinearse en la Constitución de 2008, promovida por los grupos políticos dentro de Alianza País (2007-2013), para afianzar un modelo de concentración del poder nacional no exento de controversias, dado el carácter multitendencial del proyecto en marcha.

En este artículo se pretende ilustrar aspectos del proceso de convergencia entre los modelos de gestión política de la seguridad pública y ciudadana de los gobiernos locales y del Gobierno nacional, sucesivamente, con aspectos operativos de acción comunal aportados por la Policía Nacional. El objetivo es registrar los aportes de esta institución al concepto y las prácticas de la Policía Comunitaria, en sus relaciones frente a frente y con los gobiernos locales y con el Gobierno nacional puesto que en ambos casos la posición de la policía se ha construido con diferentes estrategias de sobrevivencia institucional.

La metodología se basa en una perspectiva sistémica para descubrir las relaciones implícitas y las estrategias entre los distintos actores concurrentes en el sistema de seguridad pública y ciudadana. En este sentido, el trabajo se desarrolla en los siguientes aspectos: 1) un somero registro de las innovaciones policiales en el pasado inmediato para contextualizar el tema, 2) las influencias regionales de las prácticas de aproximación de la Policía Comunitaria, 3) la confrontación entre gobiernos locales y el Gobierno nacional por el dominio de la política de seguridad ciudadana y de la policía nacional y 4) las nuevas operaciones en busca de la construcción de confianza con la comunidad.

2 El campo de la seguridad, basada en la doctrina y Ley de Seguridad Nacional, era una atribución del Consejo de Seguridad Nacional, que aparecía como un órgano del Comando Conjunto de las Fuerzas Armadas, virtualmente distanciado del Gobierno. 


\section{Innovaciones policiales: contexto histórico}

La inseguridad cotidiana ha llegado a ser el principal problema de los ecuatorianos, por encima de los factores económicos y de desempleo, siendo ahora mismo la fuente de las mayores demandas políticas de la ciudadanía. Si bien el Gobierno ha logrado altos grados de aprobación popular, sobre todo en cuanto a la política social-que le ha permitido ganar las sucesivas contiendas electorales y consultas populares-, no ha pasado lo mismo con respecto a la inseguridad, a pesar de las inversiones realizadas en el sector.

Ganarse la confianza de los ciudadanos por parte del personal policial en un momento como este, podría ser una empresa "casi" imposible en las condiciones de la cultura de rechazo ciudadano largamente sostenidas. La institución policial en el Ecuador lleva la carga no solo de ser y haber sido una institución militarizada, con un pasado vinculado a severas acusaciones contra los derechos humanos, sino también objeto de análisis académicos con acentos de prejuicio al no haber indagado en las raíces históricas en las que surgieron las policías de fuerza pública en la región, posiblemente por la imperiosa necesidad de tener que dar cuenta de problemas sobrevenidos casi repentinamente en la realidad nacional.

Desde mediados de los 90, miembros de grados intermedios de la oficialidad plantearon medidas reformistas, no necesariamente acogidas por sus superiores ni por las autoridades políticas, pero que fructificaron en medio de los espacios de autonomía que mantuvieron las fuerzas del Estado con respecto a la política nacional. Influidos por experiencias obtenidas fuera del país, en cursos de formación o agregadurías, iniciaron operaciones de proximidad ciudadana como las brigadas barriales, unidades de policía comunitaria (UPC), servicios de emergencia a través del número telefónico 101, mesas ciudadanas de apoyo y vinculación con organizaciones civiles y empresas para obtener recursos, etc. En 2004, durante ocho meses la policía ensayó una consulta ciudadana en varias ciudades del país, incluyendo Quito y Guayaquil, con apoyo de la PUCE, que terminó con la publicación del "Plan estratégico de modernización y transformación integral de la policía 2004-2014".

Dicho plan quedó limitado por falta de asignación de fondos del Gobierno, pero fue oportuno para inducir cambios doctrinarios al interior de la institución, 
implementados en los centros de formación de oficiales. La experiencia acumulada permitió que en 2008, frente a la coyuntura constitucional impulsada por Alianza País (AP), la Policía Nacional presentara un significativo plan de reformas constitucionales.

Cuando el Gobierno de Correa asumió el protagonismo en el tema de la seguridad, dentro de la planificación estatal centralizada 2009-2013 (Plan Nacional del Buen Vivir), a cargo de la nueva Secretaría Nacional de Planificación y Desarrollo (SEMPLADES), articuló el plan policial elaborado en 2004 dentro del documento "Reformulación del plan estratégico de modernización y transformación integral de la Policía Nacional 2010-2014". ${ }^{3}$ Sin embargo, uno de los principales escollos en el emprendimiento de esta reforma, por parte del Gobierno, ha sido la dislocación de su propia política. El manejo centralizado de la seguridad ciudadana desde AP empezó a ejecutarse a través de una sucesiva emisión de decretos de emergencia, para integrar en un solo sistema todo lo hecho antes por los gobiernos locales y la Policía Nacional hasta 2007, incluyendo los propios proyectos proselitistas de AP como los comités de defensa de la revolución ciudadana (CDR), en su "Política integral de seguridad pública y ciudadana", representada en la nueva ley del mismo nombre.

Es probable que tales condiciones hayan generado los elementos de incertidumbre que llevaron al levantamiento policial del 30 de septiembre de 2010, cuyos efectos provocaron la acusación gubernamental a la institución en su conjunto por intento de "golpe de Estado" y "magnicidio", el juzgamiento de oficiales y miembros de tropa, así como la idea de poner en práctica un "Nuevo código de instituciones de seguridad policial", actualmente en espera de la aprobación por parte de la Asamblea Nacional, que supondría la extinción del actual modelo policial.

Frente a estas circunstancias, resulta curioso observar la emergencia y mantenimiento de las operaciones de la Policía Comunitaria, que continúa empren-

3 El decreto de emergencia 675, del 15 de octubre del 2007, ordenó destinar 320 millones de USD para la modernización de la policía. Una de las condiciones fue la de sacar a los uniformados a las calles y reemplazar sus puestos burocráticos por civiles. Un año después, todavía subsistían 6.000 puestos administrativos ocupados por policías. Según Fabricio Zavala, de la Unidad de Ejecución Especializada (UEE) del Ministerio de Gobierno y Policía, la finalidad es "liberar la alta carga administrativa que tenía la institución policial" (Diario Hoy, 23/11/2009). 
diendo la Policía Nacional. Es posible que, a pesar de todas las adversidades en su contra y por primera vez en su historia, los cambios implementados por la institución le permitan lograr un real y positivo posicionamiento en los ámbitos locales y comunitarios.

Además de poner de relieve la nueva aceptación que empieza a visualizarse por parte de los ciudadanos respecto a estas nuevas operaciones, debemos admitir que tenemos ante nosotros un fenómeno de interés sociológico en el ámbito de la seguridad ciudadana. Observarlo y registrarlo sistemáticamente resulta importante para medir sus proyecciones dentro de cualquier esquema institucional de respuesta ante la inseguridad.

En términos metodológicos, también se apunta a la necesidad de realizar estudios con mayor aproximación a las prácticas policiales, incluyendo aspectos de sus propias perspectivas: ¿cómo ven ellos los procesos de cambio que se proyectan desde lo político, respecto a sus campos de acción y cuáles son sus esfuerzos en busca de una legitimidad social? Al momento no se puede sostener que no existan entre los miembros policiales muchos que sinceramente buscan cambios de fondo. Al fin y al cabo, en esta última década han estado expuestos a un profundo debate sus modelos y reformas.

\section{Marcos doctrinarios de la seguridad ciudadana y la Policía Co- munitaria}

De las experiencias sobre buenas prácticas recopiladas por los informes de las organizaciones internacionales y los estudios críticos sobre prácticas específicas de seguridad ciudadana, se infiere que no existen modelos únicos en las tendencias de innovación e intervención en las policías comunitarias. Estas han surgido de las necesidades ineludibles de lograr un mejor posicionamiento policial en la comunidad y de la necesidad de emprender innovaciones constantes frente a la creatividad mostrada por el delito. Entre ellas estarían las propuestas más académicas de la OPS (Organización Panamericana de la Salud) basadas en el tratamiento de la violencia como productora de la mayor parte de los actos delictivos (epidemiología de la violencia y el delito), una propuesta que ha tenido un importante impacto en el continente. También está el modelo de 
intervención POP propuesto por David Goldstein en los años $70^{4} \mathrm{y}$ los proyectos patrocinados por la Cooperación Internacional Japonesa (JICA, 2007). De todos ellos, sin poder evitar grandes simplificaciones, se pueden destacar dos modelos tendenciales citados por los estudios relacionados con las prácticas comentadas aquí: el modelo del control (también llamado modelo situacional) y el modelo de prevención (alentado por la criminología crítica).

\section{La perspectiva situacional}

Es apreciada como más pragmática y administrativa, aplicada a operaciones sobre casos concretos más que al interés por estudiar las raíces de los problemas. La urgencia de atender las demandas ciudadanas frente al aumento de las percepciones de inseguridad, estas operaciones se orientan a dominar las situaciones y mantener el orden a toda costa. Se supone que asociada con esta estrategia está una cultura autoritaria, manifiesta en los discursos de "mano dura" y "lucha contra el crimen", y en las políticas judiciales represivas -aumento de penas, redadas en los barrios, militares en las calles. Estas medidas solo han logrado aumentar el sentimiento de inseguridad y los atropellos a los derechos humanos, con numerosos ejemplos emblemáticos en América Latina.

\section{La estrategia de prevención social y policial}

Esta se supone dirigida fundamentalmente a los factores de incidencia de la criminalidad y a la disposición de medidas anticipatorias para impedir el avance de la delincuencia. En este segundo modelo (asociado con la criminología crítica) no se presenta de modo tajante una línea divisoria entre la política criminal y la política general del Estado o del gobierno local (social, económica, urbanística). Se entiende que la prevención del delito solo es eficaz y

4 La política de seguridad pública orientada a la solución de problemas criminales (POP) es una estrategia policial para identificar y analizar los problemas de la delincuencia y el desorden, con el objeto de diseñar estrategias de respuesta que se evalúan y reorientan continuamente. Según Goldstein (1979), fundador del Center of Problem-Oriented Poicing, esto requiere un cambio de paradigmas en los métodos policiales, pues el modelo estándar de actuación policial es solamente reactivo. 
legítima cuando opera como un componente parcial y subsidiario de la política de justicia, que abarca un campo "extremamente más amplio que la restringida prospectiva de la 'lucha' contra la criminalidad" (Ávila, 2008).

El fundamento de esta segunda estrategia es la participación ciudadana para la prevención comunitaria. La participación ciudadana, desde la perspectiva de prevención y criminología crítica, no es vista como "represión comunitaria, sino como una puerta abierta a respuestas más humanísticas, más sociales, de gestión de las situaciones problemáticas". Este modelo debe estar en sintonía con el ejercicio de la democracia participativa y otorga responsabilidades al Estado (y por extensión a la policía) sobre la sociedad y hace que la comunidad entienda al Estado como un garante de sus derechos. Hace posible que el Estado y la policía estén más cercanos a la gente para compartir sus vivencias, necesidades y aspiraciones, "le pone en contacto con las diversidades sociales y situacionales existentes" (Ávila, 2008).

\section{Lo que no debe ser la participación comunitaria}

1. No debe confundirse con los modelos de la community policing, la vigilancia del vecindario y el "vigilantismo" que consiste en realizar patrullajes o turnos de vigilancia y otros que tienden a desviarse en prácticas antidemocráticas como el uso de cercados electrificados, perros agresivos y exceso de tecnología de vigilancia.

2. Son los ciudadanos los que colaboran con la policía, pero no son ellos los que pretenden cumplir el oficio de policías.

3. En el "vigilantismo" puede arrastrar a la comunidad a asumir la justicia por mano propia o a una violenta cacería de delincuentes, que en ocasiones puede generar linchamientos. Disminuye el interés en las prácticas rehabilitadoras.

4. Para evitar estas desviaciones es conveniente que se controle la participación ciudadana, dentro de los límites legales y de respeto a los derechos humanos, sin convertir a los ciudadanos en policías (Aniyar de Castro, 2003: 55-70). 


\section{Confrontación de poderes entre gobiernos locales y Gobierno nacional}

Generalmente los gobiernos locales son los que se acreditan haber sido pioneros en la introducción de las prácticas comunitarias de seguridad ciudadana. En el Ecuador, el municipio de Quito inició un proyecto de seguridad de este tipo desde 2003, frente a los requerimientos de los electores. Era la primera vez que el tema de la seguridad ciudadana estaba incluido en una campaña electoral y fue la candidatura triunfante del exgeneral Paco Moncayo para la alcaldía de Quito la que se atribuyó esta innovación. Este programa, entre otras cosas, instaló la Dirección de Seguridad Ciudadana en el gobierno municipal, puso a funcionar el sistema de cámaras de vigilancia "Ojos de águila" en el centro histórico y un observatorio metropolitano de la violencia usando las experiencias de Cali, Medellín y Bogotá.

\section{Seguridad ciudadana vs. Policía Comunitaria en los gobiernos locales: el enfoque de la seguridad ciudadana con énfasis en la salud pública ${ }^{5}$}

La Constitución de 1998 y la Ley de Descentralización del Estado y Participación Social, promulgada el 22 de octubre de 1997, había dispuesto nuevos fondos para los gobiernos locales (municipios y concejos provinciales) que quedaban facultados para pedir competencias al Gobierno, imponer tasas especiales para la seguridad en su jurisdicción y obtener créditos directos de los organismos multilaterales con el fin de dar servicios básicos a sus poblaciones. Por esta vía, los gobiernos locales se convirtieron en el eje del nuevo desarrollo humano con enfoque local que se implantó en el Ecuador a finales de los 90, en tanto que el concepto del Estado unitario se debilitaba y languidecía, concomitantemente con el fracaso de los partidos políticos que entraron en recesión. A pesar de su importancia, la situación se tornó amenazante para el sistema político nacional carente de liderazgos y mucho más para la seguridad, cuyos

5 El presente apartado usa como fundamento el estudio de Jenny Pontón (2005). 
problemas se incrementaron sin que los débiles gobiernos locales los pudieran visualizar.

El objetivo ahora es poner en contraste la política de seguridad pública del Municipio de Quito (2003), pionero de esta práctica en Ecuador, con aspectos similares de la política del Gobierno actual, y así analizar el papel jugado por la Policía Comunitaria en esas opciones.

Al obtener la competencia del manejo de la política pública de seguridad y convivencia ciudadana en 2002, el alcalde de Quito, Paco Moncayo, firmó un convenio de cooperación técnica con la OPS para facilitar el intercambio de experiencias con los municipios de Bogotá y Medellín, que ya habían iniciado el enfoque epidemiológico en sus políticas locales. En 2003 se firmó otro acuerdo con el PNUD y su proyecto de gobernabilidad local para continuar lo realizado con OPS. Con estas coberturas arrancaron los primeros talleres de análisis, con la participación de funcionarios de las diferentes áreas y administraciones, tanto del propio municipio como de otras instituciones públicas de nivel gubernamental, a las que se incorporaron organizaciones de la sociedad civil impulsadas por familiares y amigos de las víctimas del delito callejero.

Para la segunda alcaldía de Moncayo (2004-2008), el municipio ya contaba con el Plan Equinoccio 21, una planificación integral de todos los aspectos del gobierno municipal. La propuesta de seguridad ciudadana con los componentes económico, social, territorial y político, quedó circunscrita al eje social, vista por el municipio como un problema estructural en una sociedad inequitativa y excluyente. Su objetivo estratégico era hacer de Quito un territorio seguro, articulando una red de trabajo entre el municipio, la policía, la función judicial y el sistema de rehabilitación social (DMQ, 2004).

Dado que la Constitución de 1998 otorgaba autonomía al municipio y potestad de crear ordenanzas (art. 228 y 230), además de coordinar acciones con otras instituciones, sean nacionales o internacionales, el Municipio de Quito dictó las siguientes ordenanzas: 1) ordenanza que crea la tasa de seguridad, 2) ordenanza que fomenta la participación ciudadana, 3) ordenanza donde se promueven las veedurías ciudadanas, 4) ordenanza que establece las políticas tendentes a erradicar la violencia intrafamiliar y de género, 5) ordenanza de profesionalización de la policía metropolitana 6) regulación de horarios de funcionamiento de actividades comerciales y turísticas que expenden bebidas alco- 
hólicas. A partir de estas disposiciones se constituyó el "Pacto por la seguridad ciudadana", donde el municipio asumía el papel de coordinador de voluntades bajo una arquitectura institucional denominada Sistema Metropolitano de Seguridad Ciudadana, integrado, además, por la Policía Nacional, le Ministerio Público, la Dirección Nacional de Rehabilitación Social, la Corte Superior de Justicia de Pichincha y las organizaciones ciudadanas.

En cuanto a la Policía Nacional, el municipio intentaba coordinar sus acciones de Policía Comunitaria, desplegada en el modelo del "Operativo 112" gestado entre 1995 y 1996 por el coronel Mario Segovia. Segovia había tenido experiencias de observación de los kobe japoneses y otros modelos de policía comunitaria y quería lograr una réplica en el país empezando por el plan piloto en Quito. Tampoco la idea de levantar fondos e involucrar activamente a la comunidad para la seguridad era nueva. Ante el desamparo de la seguridad y la policía, por parte del Gobierno, Segovia había ideado una forma de recaudar fondos para adquirir 112 patrulleros, 112 motos, equipos de comunicación y un helicóptero. Los fondos estarían manejados por una comisión ciudadana integrada por el presidente de la Asociación de Canales de Televisión, por el presidente de la Asociación de Radiodifusoras, el presidente de la Asociación de Editores de Periódicos, un delegado de la transportación y un obispo castrense. La gestión de las "brigadas barriales" concebida por la Policía Nacional como "organización comunitaria, apolítica, de autoprotección y solidaridad ciudadana", pudo ser calificada como exitosa a no ser por las consecuencias que derivaron de esta, ajenas a la voluntad de quienes las crearon, al ser proclive a politizarse con la contaminación de actividades proselitistas por parte de los grupos políticos en el poder (Vallejo Rueda, 2009).

Con estos antecedentes, el proyecto era infinitamente más ambicioso pues creó un esquema de gobierno de la seguridad ciudadana, con una complejidad administrativa que combinaba niveles de administración local con la administración nacional, que resultaba inédita en el país. Al respecto, se ha intentado sintetizar lo más posible la situación resultante. 


\section{Tabla 1}

Niveles y partes del proyecto

\begin{tabular}{|c|c|c|}
\hline & $\begin{array}{c}\text { Nivel } \\
\text { de organización }\end{array}$ & Integrantes y componentes \\
\hline 1 & $\begin{array}{l}\text { Comisión de Segu- } \\
\text { ridad del Consejo }\end{array}$ & $\begin{array}{l}\text { Concejales municipales y alcalde: legislar y dar directrices del } \\
\text { tema, según la planificación del DMQ (2004). }\end{array}$ \\
\hline 2 & $\begin{array}{l}\text { Consejo Metropo- } \\
\text { litano de Seguridad } \\
\text { Ciudadana }\end{array}$ & $\begin{array}{l}\text { Evalúa y dicta políticas y es receptor de la rendición de cuen- } \\
\text { tas de todas las entidades que forman parte del pacto. El conse- } \\
\text { jo integrado por la Policía Nacional, el Ministerio de Gobierno, } \\
\text { Ministerio Público, Instituto Geofísico de la Politécnica Nacio- } \\
\text { nal, Intendencia de la Policía de Pichincha, representantes de los } \\
\text { medios de comunicación, al Cámara de Comercio, la Cámara de } \\
\text { Turismo y un representante de la comunidad organizada. Está } \\
\text { presidido por el alcalde. }\end{array}$ \\
\hline 3 & $\begin{array}{l}\text { Corporación Metro- } \\
\text { politana de Seguri- } \\
\text { dad Ciudadana }\end{array}$ & $\begin{array}{l}\text { Figura jurídica de derecho privado con finalidad social creada } \\
\text { el } 11 \text { de marzo del } 2002 \text { para administrar los fondos del Sistema } \\
\text { creados con la tasa de seguridad y brindar asistencia técnica. La } \\
\text { figura de persona jurídica de derecho privado es una herramienta } \\
\text { eficaz para la gestión y agilidad en el manejo de recursos y toma } \\
\text { de decisiones. }\end{array}$ \\
\hline 4 & $\begin{array}{l}\text { Dirección Metropo- } \\
\text { litana de Seguridad } \\
\text { Ciudadana }\end{array}$ & Funcionario civil \\
\hline 5 & $\begin{array}{l}\text { Apoyo técnico y } \\
\text { académico }\end{array}$ & $\begin{array}{l}\text { FLACSO, fundación ESQUEL y OPS/OMS crearon el Obser- } \\
\text { vatorio Metropolitano de Seguridad Ciudadana. Aportan con el } \\
\text { Observatorio de Seguridad del DMQ, encuestas de victimización } \\
\text { y análisis específicos. }\end{array}$ \\
\hline 6 & $\begin{array}{l}\text { Jefaturas de segu- } \\
\text { ridad ciudadana en } \\
\text { las administraciones } \\
\text { zonales y mariscal }\end{array}$ & $\begin{array}{l}\text { Ocho redes de prevención y atención, con participación de la } \\
\text { Policía Judicial, DINAPEN, ODMU, Fiscalía, comisarías de la } \\
\text { mujer y resolución alternativa de conflictos. Atención a víctimas } \\
\text { y capacitación del personal. }\end{array}$ \\
\hline
\end{tabular}




\begin{tabular}{|c|c|c|}
\hline & $\begin{array}{c}\text { Nivel } \\
\text { de organización }\end{array}$ & Integrantes y componentes \\
\hline 7 & $\begin{array}{l}\text { Policía Nacional del } \\
\text { DMQ }\end{array}$ & $\begin{array}{l}\text { En } 2002 \text { por resolución se creó el "el Servicio de la Policía Na- } \\
\text { cional para el Distrito Metropolitano de Quito". Sus funciones } \\
\text { son la planificación, organización, ejecución y control de las ac- } \\
\text { tividades de prevención y represión del delito; garantizar el orden } \\
\text { y la seguridad ciudadana con apoyo de las autoridades del DMQ } \\
\text { y la comunidad. } \\
\text { Objetivos: } \\
\text { - En el ámbito preventivo: desarrollar acciones en el control y } \\
\text { mantenimiento del orden público; llevar a cabo las acciones de } \\
\text { inteligencia, operaciones de búsqueda, seguridad de instalaciones } \\
\text { y comunicaciones, requisa de armas, municiones y explosivos y } \\
\text { campañas educativas. } \\
\text { - En el ámbito de la represión jurídica del delito: ejecutar accio- } \\
\text { nes de detención de infractores, investigación del delito, decomi- } \\
\text { so de bienes, requisa de armas, munición y explosivos y análisis } \\
\text { de evidencias. } \\
\text { - Prevención y control de la accidentalidad en tránsito en el DMQ. } \\
\text { - Creación de "casas de justicia" en el DMQ (para descentrali- } \\
\text { zar la administración de justicia con la presencia de la Fiscalía, } \\
\text { Policía Judicial, ODMU, DINAPEN, comisarías de la mujer y } \\
\text { la familia. } \\
\text { - La Policía Comunitaria, servicio policial concebido como una } \\
\text { filosofía y un nuevo estilo de policía, realiza su trabajo aprove- } \\
\text { chando la infraestructura de los Puestos de Auxilio Inmediato } \\
\text { (PAI), las Brigadas Barriales (BB) y los Retenes Policiales (RP) }\end{array}$ \\
\hline 8 & $\begin{array}{l}\text { Participación de la } \\
\text { comunidad }\end{array}$ & $\begin{array}{l}\text { Participación ciudadana en el control de la delincuencia y au- } \\
\text { mento de la confianza de la comunidad en la Policía Nacional. } \\
\text { Desarrollar un programa de capacitación en la Policía Nacional } \\
\text { con un currículo que integre materias legales y sociales, y que } \\
\text { promueva una cultura de compromiso con la comunidad. }\end{array}$ \\
\hline
\end{tabular}

Fuente: Pontón, 2005 


\section{Tabla 2 \\ Productos y proyectos desarrollados y financiados por el sistema metropolitano}

\begin{tabular}{|c|c|c|}
\hline 1 & $\begin{array}{l}\text { Observatorio Me- } \\
\text { tropolitano de Se- } \\
\text { guridad Ciudadana } \\
\text { (con apoyo acadé- } \\
\text { mico de FLACSO, } \\
\text { fuentes de la Policía } \\
\text { Nacional, Ministerio } \\
\text { Público, Dirección } \\
\text { Nacional de Género, } \\
\text { hospitales públicos) }\end{array}$ & $\begin{array}{l}\text { Observa, vigila y analiza los siguientes temas: 1) muertes por } \\
\text { causas externas 2) violencia contra las mujeres, niñas y niños 3) } \\
\text { denuncias de delitos 4) encuestas de victimización y percepción } \\
\text { de la ciudadanía sobre la delincuencia e inseguridad con el apo- } \\
\text { yo de la FLACSO 5) morbilidad hospitalaria de las enfermeda- } \\
\text { des de causa externa (lesiones) 6) estudios a profundidad sobre } \\
\text { factores de riesgo y caracterización de lesiones de causa externa } \\
\text { 7) impacto de las intervenciones. }\end{array}$ \\
\hline \multirow{2}{*}{2} & \multirow{2}{*}{$\begin{array}{l}\text { Proyectos } \\
\text { financiados } \\
\text { por la corporación }\end{array}$} & $\begin{array}{l}\text { - Sistema de Video Vigilancia: capturar y almacenar imágenes } \\
\text { en tiempo real de los sitios con mayor incidencia delincuencial } \\
\text { para promover una ágil respuesta de la Policía Nacional y de } \\
\text { otros organismos de seguridad. } \\
\text { - Central Metropolitana de Seguridad Ciudadana 101: adminis- } \\
\text { tra en forma centralizada todas las situaciones de emergencia } \\
\text { particularmente las de naturaleza delincuencial. } \\
\text { - Capacitación de operadores del sistema integrado de seguridad. } \\
\text { - Organización ciudadana "Mi barrio solidario": un sistema in- } \\
\text { tegrado de alarmas comunitarias que permita una demanda de } \\
\text { auxilio oportuna y respuesta segura. }\end{array}$ \\
\hline & & $\begin{array}{l}\text { - Construcción cuarteles: para contar con una infraestructura } \\
\text { que garantice una cobertura adecuada de áreas sensibles y una } \\
\text { respuesta oportuna y eficiente de la Policía Nacional y otras ins- } \\
\text { tituciones. } \\
\text {-Centro Metropolitano de la Equidad y la Justicia: para descen- } \\
\text { tralizar las actividades de justicia, generar nuevas alternativas de } \\
\text { solución de conflictos. } \\
\text { - Publicidad y comunicación: mantener informada a la ciudada- } \\
\text { nía y lograr opinión favorable del sistema. } \\
\text { - Vigilancia aeropolicial: proporcionar vigilancia y respuesta ae- } \\
\text { ropolicial a las demandas de auxilio en todas las manifestaciones } \\
\text { de riesgo, fundamentalmente en el tema antidelicuencial. }\end{array}$ \\
\hline
\end{tabular}




\begin{tabular}{|c|c|c|}
\hline 3 & $\begin{array}{l}\text { Central Tecnológica } \\
\text { Metropolitana de } \\
\text { Atención Ciudadana }\end{array}$ & $\begin{array}{l}\text { Desde esta central se controla el trabajo de las } 128 \text { cámaras de } \\
\text { video que están instaladas en la ciudad de Quito. } \\
\text { Cuenta con } 8 \text { operativos de auxilio y respuesta inmediata (101- } \\
\text { 901). Con la finalidad de cumplir su cometido el } 101 \text { está in- } \\
\text { terconectado con la Policía Nacional, la Cruz Roja, la Defensa } \\
\text { Civil, el Cuerpo de Bomberos, la Dirección de Emergencias 911, } \\
\text { el Ejército y otras entidades de servicio comunitario municipal } \\
\text { como la EMAAP, EMASEO, Sistema de Transporte Públi- } \\
\text { co Trolebús, Empresa Eléctrica Quito, entre otras. También se } \\
\text { cuenta con un sistema GPS, este mecanismo será instalado en } \\
\text { todos los vehículos que prestan servicio de atención de emergen- } \\
\text { cias, para facilitar su localización. } \\
\text { Áreas: 1) gestión de incidencias: donde se recepta telefónica- } \\
\text { mente las llamadas de auxilio; } 2 \text { ) radio despacho: encargada di- } \\
\text { recta de coordinar y despachar toda la logística necesaria para } \\
\text { atender las emergencias y 3) video vigilancia: que tiene como } \\
\text { función principal el control de las cámaras del sistema "Ojos } \\
\text { de águila". } \\
\text { Para } 2005 \text { existían } 3.180 \text { policías trabajando en las unidades des- } \\
\text { concentradas y se esperaba llegar a contar con 5.401 policías, } \\
\text { también está en proceso la construcción de varios cuarteles en } \\
\text { los diferentes sectores de la ciudad, además la policía del DMQ } \\
\text { cuenta con } 336 \text { vehículos para su trabajo diario. }\end{array}$ \\
\hline
\end{tabular}

Fuente: Pontón, 2005

Desde nuestra perspectiva, el caso del Municipio Metropolitano de Quito, replicado por Guayaquil y Cuenca, es paradigmático de la tendencia de las ciudades a apropiarse del tema de la seguridad ciudadana con exclusión del Estado, favorecidos por la agilidad lograda por los sistemas de gestión más moderna de los gobiernos locales basados en una planificación racional de la que en esos momentos carecía el Estado, que había privatizado algunos ámbitos de esta gestión. El objetivo era lograr una ciudad segura y en paz, por lo que la perspectiva epidemiológica o de salud pública resultaba adecuada, si bien no exenta de connotaciones localistas. 
Si se examinan las tablas expuestas, se verá que el organigrama de gestión trata de enlazar diversos planos (nacional, local, institucional), colocando en el mismo nivel de gestión política al municipio y a las funciones del Estado: Judicial y Ejecutivo. Existen elementos para pensar que los municipalistas intentaban plantear una ley para subordinar a la Policía al mando del alcalde. ${ }^{6}$ De las entrevistas se colige que el acercamiento de la institución policial a la gestión municipal representaba una oportunidad de continuar con un modelo de servicio policial que era suyo, mantener la relación con la comunidad a partir de las brigadas barriales, obtener recursos adicionales y poner a prueba la experiencia y metodología de la proximidad. El municipio, acorde con la Constitución de 1998, también creó instancias administrativas con régimen privado, para facilitar el manejo de recursos, y llegó a recaudar tasas de seguridad y fondos de la OPS y PNUD que favorecieron la acción policial.

Una encuesta sobre victimización, realizada por el municipio en 2008, permite apreciar la organización comunitaria existente en los sectores de mayor importancia de aplicación del proceso (figura 1).

Según Vallejo, los datos anteriores (figura 1, tabla 3) manifiestan las luchas de poder "por demostrar qué organización comunitaria o qué instancia del Estado debiera encabezar el tema de la seguridad ciudadana, demostrando la obsolescencia de los sistemas de gestión estatales en función de la participación, y la falta de preparación de las y los dirigentes comunitarios frente a retos contemporáneos" (Vallejo Rueda, 2009).

6 Datos de entrevistas a funcionarios policiales (se han omitido los nombres). 
Figura 1

Hogares en barrios organizados según zona administrativa

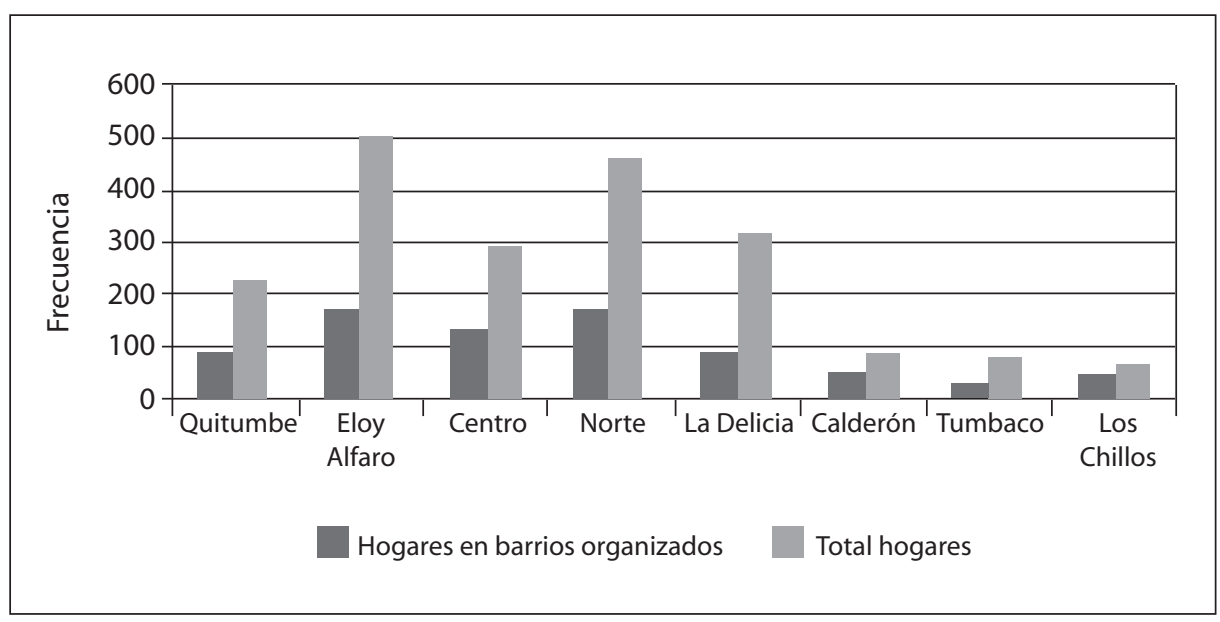

Fuente: Vallejo Rueda, 2009

Tabla 3

Formación de organizaciones

\begin{tabular}{|l|c|c|c|}
\hline \multicolumn{1}{|c|}{ Organización } & Frecuencia & Porcentaje & Válido \\
\hline Comités de seguridad & 292 & 14,3 & 37 \\
\hline Brigadas barriales & 374 & 18,3 & 47,3 \\
\hline $\begin{array}{l}\text { Comités de seguridad y brigadas } \\
\text { barriales }\end{array}$ & 105 & 5,1 & 13,3 \\
\hline Otros & 19 & 0,9 & 2,1 \\
\hline Total & 790 & 38,7 & 100 \\
\hline Valores perdidos & 1250 & 61,3 & \\
\hline Total & 2040 & 100 & \\
\hline
\end{tabular}

Fuente: Vallejo Rueda, 2009 


\section{Recuperando la autoridad nacional centralizada en el tema de la se- guridad}

En cambio, Rafael Correa se mostró dispuesto a recuperar rápidamente el liderazgo político nacional arrebatado por los gobiernos locales. De modo que la política de seguridad ciudadana empezó a registrar la pugna de poderes con los alcaldes más emblemáticos del país (Quito y Guayaquil), ajenos a AP. El presidente advirtió que la cuestión de la seguridad era un asunto estatal, dejando a los municipios lo que deben hacer (velar por el ornato de la ciudad, mantener los espacios públicos en adecuadas condiciones de iluminación y salubridad). Lo que quedó confirmado en la Constitución de 2008, que reintegró a la Policía la misión de seguridad pública y ciudadana. Fue entonces cuando se declaró a la seguridad en emergencia para poder administrar sucesivas políticas coyunturales en base a decretos.

En este nuevo esquema en el que se han juntado tanto los factores y racionalidades de la administración pública como los políticos proselitistas de AP, la organización y participación ciudadana ha quedado circunscrita al "quinto poder", el Consejo de Participación Ciudadana. Las organizaciones barriales han sido adjudicadas a las gobernaciones de las 24 provincias del país (con excepción de Pichincha, sede del Gobierno). Las mismas instancias promueven los CDR, también a cargo del Ministerio Coordinador de Seguridad. Este ministerio, que funciona al mismo tiempo como Secretaría de Consejo de Seguridad Pública y del Estado y como gestor del Sistema de Inteligencia, tiene también bajo su cargo la organización y mantenimiento del sistema ECU-911 de auxilio inmediato en todas las capitales del país, a través de un conjunto de servicios integrados (Policía Nacional, Comisión Nacional de Tránsito, Fuerzas Armadas, Cuerpo de Bomberos, Secretaría Nacional de Gestión de Riesgos, Cruz Roja) que otorgan servicios de salud y asistencia en caso de fenómenos naturales, accidentes, incendios, desastres, catástrofes, asaltos y robos. ${ }^{7}$ Su pla-

7 El sistema cuenta con dos centros nacionales (Guayaquil y Quito), 5 centros zonales (Ibarra, Portoviejo, Ambato, Cuenca y Loja), 8 centros locales (Esmeraldas, Tulcán, Nueva Loja, Santo Domingo, Babahoyo, Riobamba, Macas y Machala) y una sala de operaciones en San Cristóbal, Galápagos. 
taforma tecnológica y recursos han sido reconocidos como los más modernos de Sudamérica en cuanto a atención inmediata.

Desde antes de 2008, poco a poco la presencia del crimen complejo y organizado se hizo más evidente en el país; no solo los delitos de violencia sino los de oportunidad y la presencia de bandas y mafias empezaron a alarmar a la opinión pública y al comienzo se atribuía a los efectos de expansión de las bandas criminales desde Colombia. Para 2010, la ofuscación y el desconcierto gubernamental fue en aumento, en la medida del reconocimiento de la falta de estudios previos como sustento de las medidas tomadas, hasta el punto que el recurso de sacar a los militares a las calles a encargarse de la seguridad ciudadana ha ido en aumento. Cierto es que la puesta en marcha de esta política gubernamental en un marco de sucesivos procesos electorales no ha dejado de estar expuesta al vaivén de las luchas del poder y a las circunstancias conflictivas en las que se ha desarrollado.

¿Qué avances ha tenido la Policía Comunitaria en estos últimos años? Entrevistas realizadas y datos referentes al tema, permiten apreciar que las operaciones policiales bien pueden avanzar hacia niveles creativos de mayor acercamiento y confianza con la ciudadanía.

\section{Ensayando una nueva aproximación policía-ciudadano ante la con- gestión y el vacío}

Es innegable que la Policía ha experimentado cambios internos con una perspectiva de acercamiento a la comunidad, aprendida y observada en los casos de jóvenes policías que tuvieron la oportunidad de estudiar en otros centros del mundo. En entrevistas realizadas, encontramos que ellos consideran positiva su inserción dentro del plan municipalista que empezó en el año 2000, bajo la óptica de la descentralización de la Constitución de 1998. Allí los policías encontraron debates teóricos y prácticos, que plantearon perspectivas sociológicas focalizadas en los estudios de ciudad, así como las perspectivas epidemiológicas de la salud pública, en efecto: 
Ahora es más claro lo que deben hacer los municipios. A ellos les corresponde el alumbrado, el ordenamiento del espacio público para que no haya oportunidad de cometimiento de infracciones. Es un error que el municipio trate de dar respuestas policiales a la seguridad. El municipio tiene su propio lugar y papel [...]. La policía está sujeta a asuntos más pragmáticos del día a día. Por eso era más fácil observar y tratar de imitar el desarrollo de la Policía Comunitaria de otros países. Había un desarrollo de Policía Comunitaria que viene de los modelos de otros países. El otro modelo era simplemente el del castigo, del cual la policía quiere distanciarse. Por ello no ha dejado de ensayar constante y creativamente operaciones de Policía Comunitaria. Esto a pesar que no hay normativas políticas al respecto. Pero un paso más allá es trabajar por lograr la confianza de la gente. Hay operaciones que solo se pueden realizar porque existe confianza mutua policía-ciudadano. En estos dos últimos años, en algunos distritos y especialmente en el DMQ, se han ensayado de manera institucional nuevas operaciones: 1) recepción de denuncias y ayuda al ciudadano a ingresar al sistema de protección. Cada UPC lo hace. 2) Atención a las víctimas. 3) Operaciones de confianza como custodia de domicilios. El policía encargado realiza inspecciones y en una boleta le deja el informe al dueño de casa. 4) Custodia de bienes. Traslado de valores. El ciudadano puede solicitar este servicio policial a través del 101. 5) Guía de movilización de bienes muebles. Los transportes de mudanzas deben contar con una guía proporcionada por la policía (frente a los numerosos robos de domicilio por parte de individuos que simulan mudanzas). 6) Sistema de las alarmas individuales por el 101, se ha llegado a records de atención de cuatro minutos. 7) Respuestas y atención por el sistema 911 del Estado".

Estos servicios policiales son, en cierta manera, programas piloto a incrementarse en la medida en que lo haga la confianza ciudadana de la cual dependen. ${ }^{9}$ Un reporte detallado de la puesta en práctica de las operaciones mencionadas, durante el año y medio de ensayos, se muestra a continuación.

8 Entrevista al comandante de la zona 9 del DMQ, julio, 2013.

9 Entrevistas a miembros de estas agrupaciones. 
Tabla 4

Datos estadísticos de la Policía Nacional (2012)

\begin{tabular}{|l|c|c|c|c|c|c|c|c|c|c|c|c|c|}
\hline \multicolumn{10}{|c|}{ Comando de policía de la zona 9 DMQ } \\
\hline Actividad & Enero & Febrero & Marzo & Abril & Mayo & Junio & Julio & Agosto & $\begin{array}{c}\text { Septiem- } \\
\text { bre }\end{array}$ & Octubre & $\begin{array}{c}\text { Noviem- } \\
\text { bre }\end{array}$ & $\begin{array}{c}\text { Diciem- } \\
\text { bre }\end{array}$ & Total \\
\hline $\begin{array}{l}\mathrm{N}^{\circ} \text { de } \\
\text { auxilios } \\
\text { atendidos }\end{array}$ & 1.062 & 1.110 & 1.061 & 919 & 927 & 783 & 873 & 1.001 & 954 & 1.021 & 989 & 835 & 11.535 \\
\hline $\begin{array}{l}\mathrm{N}^{\circ} \text { de } \\
\text { custodia de } \\
\text { valores reali- } \\
\text { zados }\end{array}$ & 441 & 753 & 718 & 697 & 730 & 863 & 853 & 633 & 703 & 987 & 807 & 637 & 8.822 \\
\hline $\begin{array}{l}\text { Requeri- } \\
\text { miento de } \\
\text { autoridades } \\
\text { competentes } \\
\text { atendidas } \\
\text { (boletas) }\end{array}$ & 1.045 & 1.114 & 1.227 & 1.153 & 1.268 & 1.089 & 1.261 & 1.399 & 1.364 & 1.467 & 1.453 & 1.002 & 14.842 \\
\hline
\end{tabular}

Fuente: Comando de Policía $N^{\circ} 9$

Tabla 4

Datos estadísticos de la Policía Nacional (2013)

\begin{tabular}{|c|c|c|c|c|c|c|c|c|c|c|c|c|c|}
\hline \multicolumn{14}{|c|}{ Comando de policía de la zona 9 DMQ } \\
\hline Actividad & Enero & Febrero & Marzo & Abril & Mayo & Junio & Julio & Agosto & $\begin{array}{c}\text { Septiem- } \\
\text { bre }\end{array}$ & Octubre & $\begin{array}{c}\text { Noviem- } \\
\text { bre }\end{array}$ & $\begin{array}{c}\text { Diciem- } \\
\text { bre }\end{array}$ & Total \\
\hline $\begin{array}{l}\text { No. De auxi- } \\
\text { lios atendidos }\end{array}$ & 9.058 & 8.327 & 10.988 & 10.877 & 8.935 & 11.889 & & & & & & & 60.074 \\
\hline $\begin{array}{l}\text { No. De Custo- } \\
\text { dia de Valores } \\
\text { realizados }\end{array}$ & 1.237 & 1.046 & 1.428 & 1.618 & 1.546 & 1.558 & & & & & & & 8.433 \\
\hline $\begin{array}{l}\text { Requerimiento } \\
\text { de autoridades } \\
\text { competentes } \\
\text { atendidas } \\
\text { (boletas) }\end{array}$ & 2.220 & 2.135 & 2.871 & 1.909 & 1.799 & 1.970 & & & & & & & 12.904 \\
\hline
\end{tabular}

Fuente: Comando de Policía $\mathrm{N}^{\circ} 9$ 


\section{Conclusiones}

La primera década de 2000, tras la firma de la paz con el Perú, representó para el Ecuador que estrenaba una nueva piel territorial, una época de convulsiones políticas, acentuación de los viejos regionalismos que vienen desde la época colonial. La reforma del Estado, consagrada en la Constitución de 1998 basada en la descentralización y en un esquema neoliberal fortaleció momentáneamente a los gobiernos locales en desmedro de lo nacional y estatal en medio de la crisis financiera y bancaria. La desarticulación nacional y el desempleo favorecieron la intempestiva migración de la mano de obra y las familias hacia otros países, agudizaron la inseguridad y cimentaron las esperanzas populares hacia liderazgos surgidos por fuera del sistema político, aglutinados en AP. Entre otras cosas, la recuperación de los precios del petróleo en esta coyuntura mundial, ha coadyuvado para que este liderazgo permita una política nacional de desarrollo planificado basado en las regiones y no en los municipios, pero al parecer, con las intenciones puestas más en la captación del voto popular a través del fincados en servicios estatales de calidad (salud, vialidad, educación, subsidios y bonificaciones).

En el tema de la seguridad las cosas son bastante distintas, el retardo estratégico del país por el mantenimiento de las viejas perspectivas de la seguridad nacional no permitió que funcionarios civiles accedan oportunamente a la experiencia del control civil de la defensa y la seguridad pública. Los proyectos actuales de reforma desde el Ejecutivo están supeditados más a las estrategias políticas de consolidación de un movimiento y un liderazgo nacional que busca su permanencia (incluso a través de sucesivos cambios constitucionales) a partir del poder popular de un líder carismático. Al momento todas las instituciones del Estado están en reconstrucción o en realineamiento con el ejecutivo. $\mathrm{Si}$ el proceso tiene futuro más allá de la vigencia de este liderazgo es algo que no es posible prever. La modalidad de control civil en implementación incluye la coopción de las instituciones de fuerza (más cercana al control subjetivo en los términos de Huntington). Las reformas del gobierno pretenden un posicionamiento rápido con métodos de ensayo-error. Las reformas policiales ejecutadas en el desarrollo de su concepto de Policía Comunitaria siguen adelante y ha sido el objeto de estudio de nuestra ponencia. El estudio muestra tan solo un 
aspecto específico de la implementación de innovaciones operativas de una institución que busca su supervivencia en base a la construcción de confianza con la ciudadanía. Constreñida por los estrechos espacios doctrinarios señalados más arriba, por su larga condición de subalternidad de misiones y antagonismo con las Fuerzas Armadas.

\section{Bibliografía}

\section{Libros y documentos}

Aniyar de Castro, A.

2003 "El abolicionismo en marcha: nuevos modelos de control. Participación ciudadana y policía comunitaria. El caso de América Latina”, pp. 55-70.

Ávila, K.

2005 “Aproximación a las propuestas de prevención y control del delito desde la criminología crítica”. En: Revista Capítulo Criminológico. Vol. 33. No 2. Venezuela. Instituto de Criminología Lolita Aniyar de Castro, pp. 225-265.

Ávila, K.

2008 "Estudio de la participación comunitaria o ciudadana como modalidad de una política criminal preventiva". En: Revista Electrónica Derecho Penalonline. Disponible en: http://www.derechopenalonline.com/derecho. php?id=27,348,0,0,1,0 [17 de julio de 2013].

Benítez Manaut, R.

s/f. "La nueva seguridad hemisférica. Después de México ¿hacia dónde?”. Disponible en: http://www.resdal.org/campo/art-news-benitez.html

Blanco, C. G.

s/f. "Policía comunitaria". Bs. As. Instituto Universitario de Gendarmería Nacional.

Espinosa Villagómez, S.

2013 "El control político de la delincuencia en el Gobierno del presidente Correa. Una estrategia de legitimación". Tesis de Licenciatura en Sociología de la Pontificia Universidad Católica del Ecuador. Quito.

Gallardo León, C.

2009 "Encuestas de victimización en Ecuador". En: Boletín Ciudad Segura. FLACSO. N ${ }^{\circ}$ 37.Goldstein, G.

1979 Problem Oriented Policing. McGraw-Hill. 
Pontón, J.

2005 La seguridad ciudadana en Quito, Guayaquil y Cuenca: modelos de interVallejo Rueda, O. vención. Quito: FLACSO.

2009 "Participación comunitaria en la seguridad ciudadana: la experiencia de Quito". En: Boletín Ciudad Segura. №34. Quito: FLACSO.

\section{Leyes y decretos del Ecuador}

Constitución de la República del Ecuador

2008 Disponible en: http://www.asambleanacional.gov.ec/documentos/constitucion_de_bolsillo.pdf

Ley de Seguridad Nacional de Ecuador

1979 Disponible en: http://atlas.resdal.org/Archivo/d0000285.htm

Código Orgánico de Organización Territorial, Autonomía y Descentralización

2010 Disponible en: http://www.dirnea.org/data/leyes_y_reglamentos/Leyes $\% 20$ Generales\%20PDF/codigo_organico_organizacion_territorial.pdf

Plan Estratégico de Desarrollo del Distrito Metropolitano de Quito

2005 Secretaría Técnica del Municipio del DMQ, abril de 2005. Disponible en: http:/www.docstoc.com/docs/113941102/Equinoccio-21-Quito-haciael-2025

Reforma a la Ordenanza de Seguridad y Convivencia Ciudadanas

2006 Sancionada el 13 de diciembre de 2006.

Sistema Integrado de Seguridad

s/f. Disponible en: http://www.seguridad.gob.ec/sistema-integrado-de-seguridad-ecu-911/

\section{Artículos de prensa}

Diario Hoy (28/07/2004) "Policía arma su nuevo plan estratégico".

Diario Hoy (23/11/2009) "El decreto de emergencia [...] ordenó destinar \$320 millones para la modernización de la policía".

Noticias en Línea (30/09/2011) "Proyecto de Código Orgánico de Entidades de Seguridad Ciudadana fue entregado a la Asamblea". Disponible en: http://noticiasenlinea. com.ec/politica/19963_proyecto-de-codigo-organico-de-entidades-de-seguridad-ciudadana-fue-entregado-a-la-asamblea.html

Diario Hoy (29/06/1996) "La policía busca fondos para seguridad". Disponible en: http://www.explored.com.ec/noticias-ecuador/la-policia-busca-fondos-para-seguridad-4864.html 
Diario Expreso (30/04/2006) "Fracasó plan municipal de control con guardias privados".

El Universo (09/10/2009) "La inseguridad de Guayaquil enfrentó a Correa y Nebot". Disponible en: http://www.eluniverso.com/2009/10/10/1/1355/inseguridad-guayaquilenfrento-correa-nebot.html

Diario la Hora (13/07/2012) "Ecuador es víctima del sicariato". Disponible en: http://www.lahora.com.ec/index.php/noticias/show/1101360735/-1/Ecuador es_v\%C3\%ADctima_del_sicariato.html\#.UgPShdLryE4

Diario Expreso (30/04/2006) "Fracasó plan municipal de Guayaquil de control de seguridad con guardias privados". Disponible en:

http://www.ecuadorinmediato.com/index.php? module=Noticias\&func=news_user_ view\&id=33313\&umt=expreso_guayaquil_fracaso_plan_municipal_control_con_ guardias_privados

\section{Organismos internacionales}

Organización de Estados Americanos

2006 "Plan de acción hemisférico contra la delincuencia organizada transnacional". (Aprobada en sesión celebrada el 25 de octubre de 2006). Disponible en: http://www.oea.org/consejo/sp/resoluciones/res908.asp

Organización de las Naciones Unidas

2000 "Propuestas y contribuciones recibidas por los gobiernos". Comité especial encargado de elaborar una convención contra la delincuencia organizada transnacional. Disponible en: http://www.uncjin.org/Documents/Conventions/dcatoc/7session/5a17s.pdf

Japan International Cooperation Agency

2007 "Los koba japoneses arraigan en América Latina". Disponible en: http:// www.jica.go.jp/english/news/field/archive/2007/index.html

\section{Entrevistas}

Entrevista al Comandante de la zona 9 del DMQ, Quito, julio, 2013.

Envío 3 de octubre/2013 - Aceptación 17 de diciembre/2013 